\title{
SILICASUPPORTED COPPER(II) OXIDE FOR THE SYNTHESIS OF CURCUMIN DERIVATIVES CONTAINING PYRAZOLE AND ISOXAZOLE SCAFFOLDS
}

\author{
Antonius Herry Cahyana*, Bayu Ardiansah and Wahyu Hidayat Ibrahim \\ Department of Chemistry, FMIPA, Universitas Indonesia, 16424, Depok, Indonesia \\ *E-mail : herrykim@ui.ac.id
}

\begin{abstract}
Preparation of $\mathrm{CuO} / \mathrm{SiO}_{2}$ catalyst has been done via sol-gel method using copper nitrate solution and TEOS as precursors. Several instruments such as FT-IR, SEM, EDAX, XRD and particle sizer were employed to characterize the obtained material. Then, $\mathrm{CuO} / \mathrm{SiO}_{2}$ catalyst was successfullyusedin the synthesis of three curcumin derivatives, 4,4'-((1E,1'E)-(1H-pyrazole-3,5-diyl)bis(ethene-2,1-diyl))bis(2-methoxyphenol) (Compound 1), 4,4'-((1E,1'E)-(1phenyl-1H-pyrazole-3,5-diyl)bis(ethene-2,1-diyl))bis(2-methoxyphenol) (Compound 2) and 4,4'-((1E,1'E)(isoxazole-3,5-diylbis(ethene-2,1-diyl))bis(2-methoxyphenol) (Compound 3) with good yields.

Keywords: Heterogeneous Catalyst, Curcumin, Pyrazole, Isoxazole.
\end{abstract}

(C) RASĀYAN. All rights reserved

\section{INTRODUCTION}

Curcumin is a polyphenol compound present in Curcuma longa L. rhizomes (turmeric). ${ }^{1}$ Along with demethoxycurcumin and bisdemethoxycurcumin, they are called curcuminoids. It mainly contributes to pharmacological activities of turmeric, such as antioxidant and antimicrobial. ${ }^{2-4}$ Curcumin has been known to demonstrate a wide spectrum of bioactivities like anticancer, antitumor, anti-inflammatory, antidiabetic and analgesic properties ${ }^{5-9}$ However, the potential utility of curcumin as therapeutics molecule is limited due to its poor bioavailability. The presence of 1,3-diketone moiety makes it quickly decomposed in neutral and basic conditions. ${ }^{10-12}$ To circumvent the problem of rapid degradation and metabolism, there is a challenge to modify curcumin structure, specifically in active methylene and carbonyl groups. ${ }^{13}$

Pyrazole and isoxazole are aromatic five-membered heterocyclic molecules constituted by three carbons and existence of N-N or N-O bond, respectively. These moieties in secondary metabolites are rare. ${ }^{14}$ Even though, they play a prominent role in medicinal chemistry because of pyrazole and isoxazole scaffolds found in many marketed drugs, such as celecoxib (anti-inflammatory), rimonabant (anti-obesity), fezolamine (antidepressant), sulfamethoxazole and cycloserine (antibiotics). ${ }^{15-17}$ In this line of continuation to obtain pyrazole and isoxazole derivatives of curcumin, we report the synthesis of three derivative compounds using $\mathrm{CuO} / \mathrm{SiO}_{2}$ catalyst.

\section{Materials}

\section{EXPERIMENTAL}

Chemicals used were an analytical grade, such as curcumin for synthesis (Merck), hydrazine hydrate (Sigma-Aldrich), hydroxylamine hydrochloride (Sigma-Aldrich), tetraethyl orthosilicate (Merck), glycerol (Merck), $\mathrm{HNO}_{3}$ (Merck), glacial acetic acid (Merck), ethanol (Merck). Infrared spectra were recorded on Shimadzu Prestige 21 spectrophotometer, whereas UV-Vis spectra on Shimadzu UV Visible spectrophotometer model UV-mini 1240. The size distribution was measured using Beckman Coulter LS 13320 particle sizing analyzer. Identification of organic compounds was done by UPLC-MS ACQUICITY UPLC H-Class Xevo G2-S QTof. Morphology and elemental composition were analyses using Zeiss MultiSEM505 tandem EDAX instruments.

Rasayan J. Chem., 12(2), 471-477(2019)

http://dx.doi.org/10.31788/RJC.2019.1225011 


\section{Preparation of $\mathrm{CuO} / \mathrm{SiO}_{2}$ Catalyst}

Copper nitrate $(1 \mathrm{M})$, TEOS $(10 \mathrm{ml})$ and glycerol $(5 \mathrm{ml})$ were mixed in a $100 \mathrm{ml}$ Erlenmeyer flask. Then, the $\mathrm{pH}$ of the solution was adjusted to 1.5 by adding dilute nitric acid. The mixture was stirred for $3 \mathrm{~h}$ while ammonia was added dropwise until $\mathrm{pH}$ 8-9. The resulting gel was filtered and washed with ethanol. It was stored in water/ ethanol 1:1 solvent for 48-72 $\mathrm{h}$. The mixture was filtered and the residue was dried in an oven at $100^{\circ} \mathrm{C}$ for $3 \mathrm{~h}$. Subsequently, the residue was calcined at $500^{\circ} \mathrm{C}$ for $5 \mathrm{~h}$ to produce $\mathrm{CuO} / \mathrm{SiO}_{2} \cdot{ }^{18}$

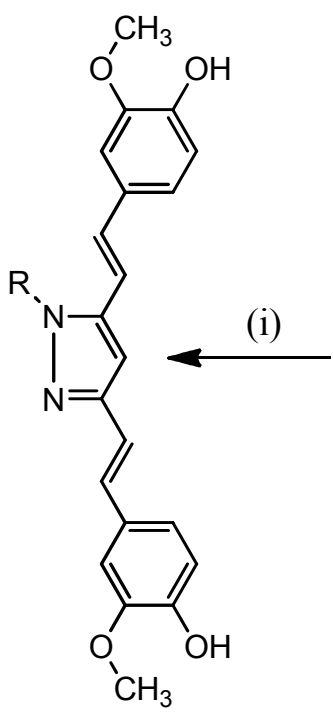

Compound $1(\mathrm{R}=\mathrm{H})$

Compound $2(\mathrm{R}=\mathrm{Ph})$

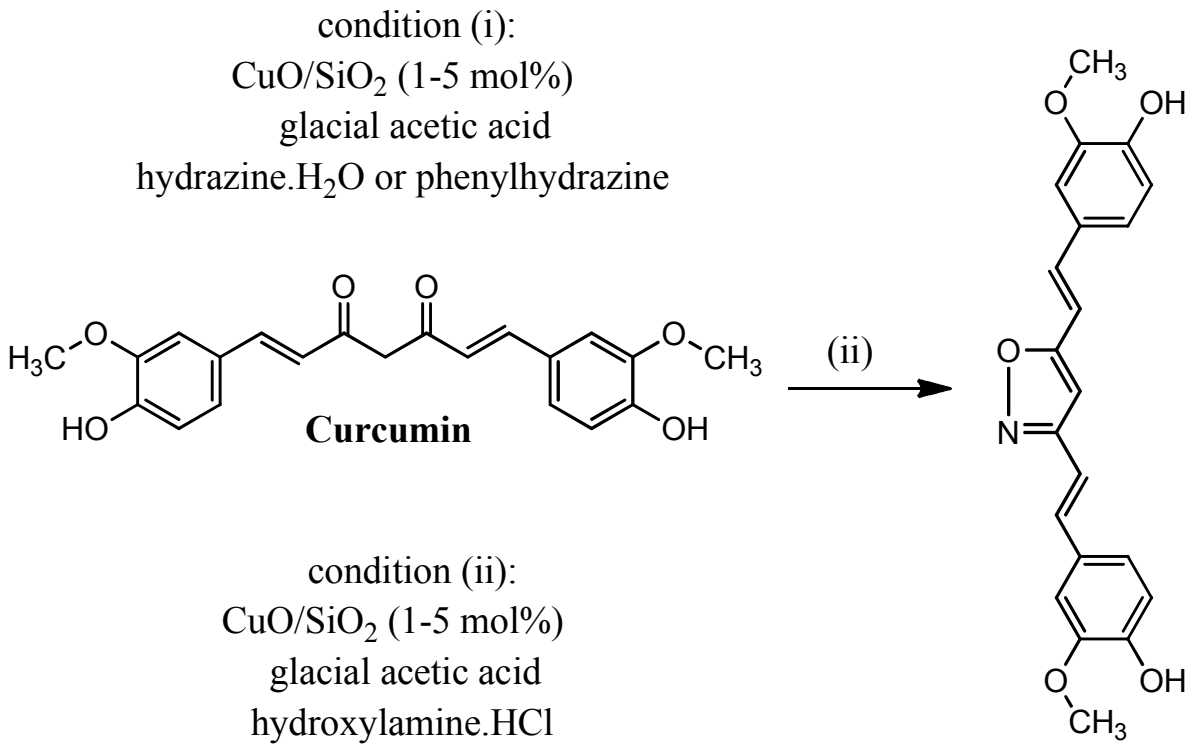

Compound 3

Fig.-1: Scheme of the Synthesis of Curcumin Derivatives

\section{Synthesis of Curcumin Derivatives}

In a $50 \mathrm{ml}$ round-bottom flask equipped with condenser, a mixture containing curcumin $(0.6 \mathrm{mmol})$, hydrazine hydrate $(2.25 \mathrm{mmol})$, and glacial acetic acid $(5 \mathrm{ml})$ was stirred in the presence of different amount of catalyst $(0-5 \% \mathrm{~mol})$ for various reaction time $(6,7,8$ and $9 \mathrm{~h})$ at specified temperature $(60,70,80$ or $90^{\circ} \mathrm{C}$ ). After filtration to separate the catalyst, the filtrate was extracted two times with $15 \mathrm{ml}$ of ethyl acetate:water (1:1) for each process. Anhydrous sodium sulfate was added to the combined organic fraction to remove water molecules. The fraction was subjected to vacuum evaporator to yield a crude product. It was then recrystallized from hot ethanol to obtain Compound 1. Meanwhile, the synthesis of Compound 2 and Compound 3 was performed using optimized conditions by changing hydrazine hydrate with phenylhydrazine $(2.25 \mathrm{mmol})$ or with hydroxylamine hydrochloride $(1.5 \mathrm{mmol})$.

\section{Catalyst Characterization}

\section{RESULT AND DISCUSSION}

Silica and materials containing silica have been widely used in many fields because of its prominent properties. ${ }^{19-22}$ Herein, we reported the preparation of silica-supported copper(II) oxide catalyst. FT-IR spectrum of $\mathrm{CuO} / \mathrm{SiO}_{2}$ catalyst (Fig.-2a) showed the typical asymmetric stretch of $\mathrm{Cu}-\mathrm{O}$ at $470 \mathrm{~cm}^{-1}$. Meanwhile, the peaks centered at 1090 and $805 \mathrm{~cm}^{-1}$ were observed due to deformation of Si-O bond. ${ }^{23}$ The $\mathrm{CuO} / \mathrm{SiO}_{2}$ material also showed a band at $960 \mathrm{~cm}^{-1}$. It is due to the overlapping between the $\mathrm{Si}-\mathrm{OH}$ bond and $\mathrm{Si}-\mathrm{O}$ bending vibration. ${ }^{24}$ The intense peaks at 3410 and $1620 \mathrm{~cm}^{-1}$ correspond to hydroxyl groups and absorbed water to the $\mathrm{CuO} / \mathrm{SiO}_{2}$ surface.

The XRD patterns of the prepared $\mathrm{CuO} / \mathrm{SiO}_{2}$ was depicted in Fig.-2(b). It can be clearly observed that the few sharp peaks are seen at diffraction angles (2 theta) of $35.4^{\circ}, 38.6^{\circ}, 48.8^{\circ}, 53.5^{\circ}, 58.3^{\circ}, 61.5^{\circ}, 66.2^{\circ}, 68.0^{\circ}$, and $72.3^{\circ}$. These peaks are fit with the literature No. 48-1548 (JCPDS data Card) of the monoclinic copper 
oxide. ${ }^{25,26}$ There was no presence of peaks for silica because it is an amorphous material. ${ }^{23} \mathrm{CuO} / \mathrm{SiO}_{2}$ morphology was observed by SEM, and the micrograph was shown in Fig.-2c. Because of its considerable porosity and structure rigidity, silica is prominent support for various catalysts. ${ }^{23}$
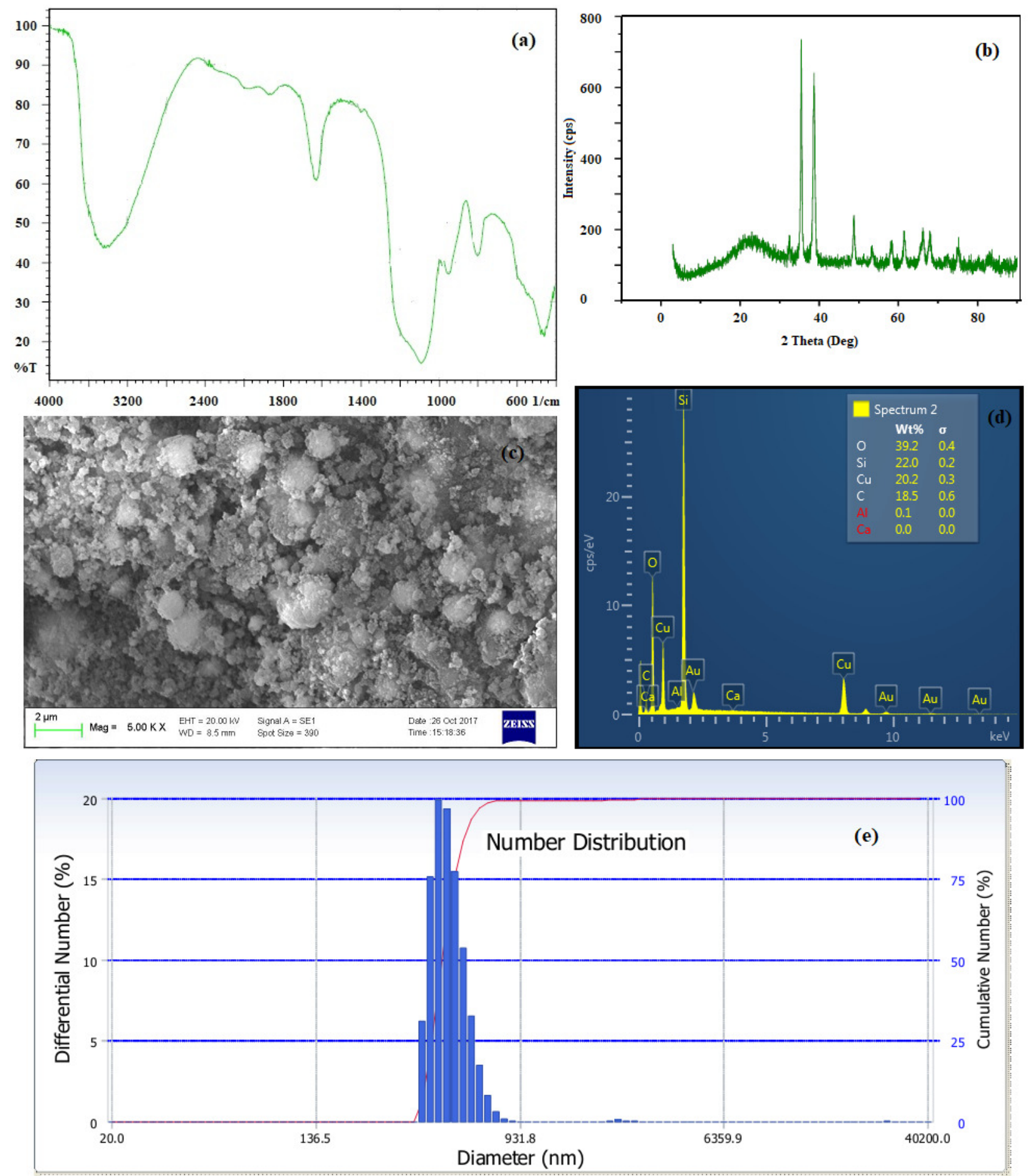

Fig.-2: (a) FT-IR Spectrum, (b) XRD Pattern, (c) SEM Image, (d) EDAX Spectrum and (e) Size Distribution of the Prepared Catalyst

In this case, the $\mathrm{SEM}$ image of $\mathrm{CuO} / \mathrm{SiO}_{2}$ showed impregnation of copper oxide on the silica surface. Discontinuity and rough surface of prepared material signified the success of impregnation process. The elemental content of the prepared $\mathrm{CuO} / \mathrm{SiO}_{2}$ was measured using energy dispersive X-ray (EDAX) analysis 
RASĀYAN J. Chem.

Vol. 12 | No. 2 |471 - 477| April - June | 2019

(Fig.-2d). EDAX spectrum of catalyst revealed the intense peaks of silicon ( $\mathrm{Si}$ ) and oxygen $(\mathrm{O})$. Few appeared peaks of copper $(\mathrm{Cu})$ indicated that the obtained material is principally composed by silica with a trace of copper oxide. ${ }^{27}$ Analysis using particle sizer (Fig.-2e) was done to obtain the size distribution of $\mathrm{CuO} / \mathrm{SiO}_{2}$. The average size of this material was $525.1 \mathrm{~nm}$.

\section{Synthesis of Curcumin Derivatives}

The cyclization reaction between curcumin and hydrazine hydrate was first carried out at $80^{\circ} \mathrm{C}$ in the presence of $1 \mathrm{~mol} \%$ of $\mathrm{CuO} / \mathrm{SiO}_{2}$ catalyst for 6-9 h. The highest yield was obtained after $8 \mathrm{~h}$ reaction time in continuous stirring equipped with a condenser (Table-1 Entry 3). The temperature was also varied from $60-90^{\circ} \mathrm{C}$. Moreover, we observed the reaction in the absence of a catalyst. Resultantly, the yield of product was only $59 \%$. Raising the amount of catalyst from 1 to 2.5 or $5 \mathrm{~mol} \%$ did not increase the yield of Compound 1. Therefore, we presume that Entry 3 with detailed conditions is the best procedure to synthesize this compound. Under the same condition, we have synthesized Compound 2 and 3 with 81 and $80 \%$ yield, respectively (Table-2).

Table-1: Optimization in the Synthesis of Compound 1

\begin{tabular}{c|c|c|c|c}
\hline Entry & Time $(\mathrm{h})$ & $\mathrm{T}\left({ }^{\circ} \mathrm{C}\right)$ & Catalyst (mol\%) & Yield (\%) \\
\hline 1 & 6 & 80 & 1 & 60 \\
\hline 2 & 7 & 80 & 1 & 64 \\
\hline 3 & 8 & 80 & 1 & 85 \\
\hline 4 & 9 & 80 & 1 & 78 \\
\hline 5 & 8 & 60 & 1 & 82 \\
\hline 6 & 8 & 70 & 1 & 81 \\
\hline 7 & 8 & 90 & Free & 59 \\
\hline 8 & 8 & 80 & 2.5 & 80 \\
\hline 9 & 8 & 80 & 5 & 82 \\
\hline 10 & 8 & 80 & 1 & 70 \\
\hline
\end{tabular}

Reaction conditions: curcumin $(0.60 \mathrm{mmol})$, hydrazine hydrate $(2.25 \mathrm{mmol})$, absence or presence of

$\mathrm{CuO} / \mathrm{SiO}_{2}$ catalyst. The reaction was carried out in a round-bottom flask equipped with a condenser.

Table-2: Characterization Data and Yield of Curcumin Derivatives

\begin{tabular}{|c|c|c|c|}
\hline Compd. & Structure & Characterization Data & $\begin{array}{c}\text { Yield } \\
(\%)\end{array}$ \\
\hline 1 & & $\begin{array}{l}\text { Orange solid. IR }(1 / \mathrm{cm}): 3560(\mathrm{O}-\mathrm{H}), 3320 \\
(\mathrm{~N}-\mathrm{H}), 3050-3010\left(\mathrm{C}-\mathrm{H} \mathrm{sp}{ }^{2}\right), 2940-2850 \\
\left(\mathrm{C}-\mathrm{H} \mathrm{sp} \mathrm{sp}^{3}\right), 1602(\mathrm{C}=\mathrm{C}), 1563(\mathrm{C}=\mathrm{N}), 1480 \\
\text { (phenyl ring), } 1140(\mathrm{C}-\mathrm{O}) . \mathrm{UV}-\mathrm{Vis}(\mathrm{nm}): \\
\text { 326. HRMS }(\mathrm{m} / \mathrm{z}): 365.1499\left([\mathrm{M}+1]^{+}\right) .\end{array}$ & 85 \\
\hline 2 & & 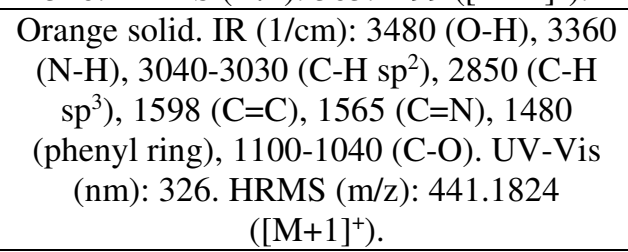 & 81 \\
\hline 3 & & $\begin{array}{l}\text { Brown solid. IR }(1 / \mathrm{cm}): 3481(\mathrm{O}-\mathrm{H}), 3325 \\
(\mathrm{~N}-\mathrm{H}), 3030-3005\left(\mathrm{C}-\mathrm{H} \mathrm{sp}{ }^{2}\right), 2950-2900 \\
\left.(\mathrm{C}-\mathrm{H} \mathrm{sp})^{3}\right), 1597(\mathrm{C}=\mathrm{C}), 1524(\mathrm{C}=\mathrm{N}), 1440 \\
(\text { phenyl ring }), 1070(\mathrm{C}-\mathrm{O}) . \mathrm{UV}-\mathrm{Vis}(\mathrm{nm}): \\
\text { 421, 334. MS }(\mathrm{m} / \mathrm{z}): 366.1352\left([\mathrm{M}+1]^{+}\right) .\end{array}$ & 80 \\
\hline
\end{tabular}


RASĀYAN J. Chem.

Vol. 12 | No. 2 |471 - 477| April - June | 2019
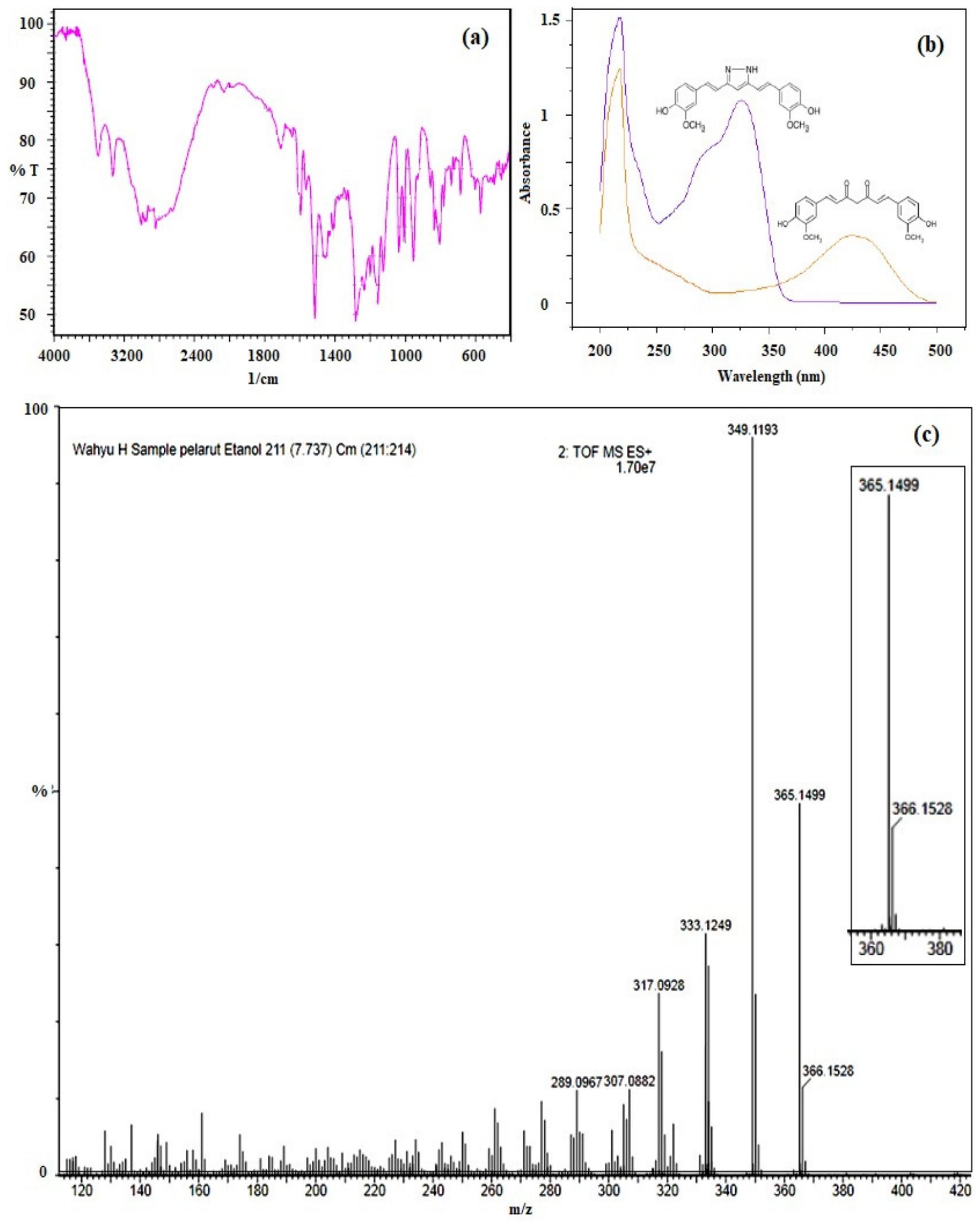

Fig.-3: (a) FT-IR, (b) UV-Vis and (c) MS Spectra of Selected Curcumin Derivatives (Compound 1) 
RASĀYAN J. Chem.

Vol. 12 | No. 2 |471 - 477| April - June | 2019

\section{Characterization of Curcumin Derivatives}

Figure-3(a) showed the FT-IR spectrum for the synthesized Compound 1, where it is possible to see the presence of characteristic functionalities such as $\mathrm{O}-\mathrm{H}$ stretching vibration occurs at approximately 3560 $\mathrm{cm}^{-1}$. The peak of $\mathrm{C}=\mathrm{N}$ in pyrazole skeleton is mainly observed in the spectrum at $1563 \mathrm{~cm}^{-1}$. A band near $1602 \mathrm{~cm}^{-1}$ is corresponds to $\mathrm{C}=\mathrm{C}$ bond of olefin exist. Also, bands for stretching vibration of $\mathrm{sp}^{2}$ and $\mathrm{sp}^{3} \mathrm{C}$ $\mathrm{H}$ are located at 3050-3010 and 2940-2850 $\mathrm{cm}^{-1}$, respectively. At $1480 \mathrm{~cm}^{-1}$ the band assigned to the phenyl ring vibration, and at $1140 \mathrm{~cm}^{-1}$ the peak band of C-O appears. In UV-Vis analysis (Fig.-3b), the typical bathochromic effect was found due to the decrease of a number of conjugated double bonds in the structure. Compound 1 has a maximum wavelength at $321 \mathrm{~nm}$, whereas curcumin as starting material at $423 \mathrm{~nm}$. Meanwhile, Compound 2 has also $326 \mathrm{~nm}$ of maximum wavelength, whereas Compound 3 has two major absorptions at 421 and $334 \mathrm{~nm}$. Confirmation of product structures was done by mass spectrometry (Fig.$3 \mathrm{c})$. These three compounds have $[\mathrm{M}+1]^{+}$peak at MS spectra. All characterization data are in agreement with previously reported works. ${ }^{1,28,29}$

\section{CONCLUSION}

We described the preparation and characterization of $\mathrm{CuO} / \mathrm{SiO}_{2}$ catalyst via sol-gel method. The $\mathrm{CuO} / \mathrm{SiO}_{2}$ was successfully applied as an efficient catalyst in the synthesis of three curcumin derivatives integrated with pyrazole and isoxazole moieties. The organic products were obtained in good yields.

\section{ACKNOWLEDGMENT}

This work was financially supported by Directorate General of Higher Education (DIKTI), the Republic of Indonesia through PenelitianUnggulanPerguruanTinggi (PUPT) 2017 with contract No. 2967/ADD/UN2.R3.1/HKP05.00/2017.

\section{REFERENCES}

1. H.R. Puneeth, H. Ananda, K.S.S. Kumar, K.S. Rangappa and A.C. Sharada, Medicinal Chemistry Research, 25, 1842(2016), DOI: 10.1007/s00044-016-1628-5

2. E.M. Tanvir, M.S. Hossen, M.F. Hossain, R. Afroz, S.H. Gan, M.I. Khalil, et al., Journal of Food Quality, 2017, Article ID 8471785 (2017), DOI: 10.1155/2017/8471785

3. P. Gul and J. Bakht, Journal of Food Science and Technology, 52(4), 2272(2015), DOI: 10.1007/s13197-013-1195-4

4. S. Mosovska, P. Petakova, M. Kalinak and A. Mikulajova, Acta Chimica Slovaca, 9(2), 130 (2016), DOI: $10.1515 /$ acs-2016-0022

5. A.K. Panda, D. Chakraborty, I. Sarkar, T. Khan and G. Sa, Journal of Experimental Pharmacology, 9, 31 (2017), DOI: 10.2147/JEP.S70568

6. F. Liu, S. Gao, Y. Yang, X. Zhao, Y. Fan, W. Ma, et al., Oncology Reports, 39(3), 1523 (2018), DOI: 10.3892/or.2018.6188

7. R.L. Edwards, P.B. Luis, P.V. Varuzza, A.I. Joseph, S.H. Presley, R. Chaturvedi, et al., Journal of Biological Chemistry, 292(52), 21243 (2017), DOI: 10.1074/jbc.RA117.000123

8. T Nishiyama, T. Mae, H. Kishida, M. Tsukagawa, Y. Mimaki, M. Kuroda, et al., Journal of Agricultural and Food Chemistry, 53(4), 959 (2005), DOI:10.1021/jf0483873

9. K.A. Agarwal, C.D. Tripathi, B.B. Agarwal and S. Saluja, Surgical Endoscopy, 25(12), 3805 (2011), DOI: $10.1007 / \mathrm{s} 00464-011-1793-\mathrm{Z}$

10. P. Anand, A.B. Kunnumakkara, R.A. Newman and B.B. Aggarwal, Molecular Pharmaceutics, 4(6), 807 (2007), DOI:10.1021/mp700113r

11. M.H. Pan, T.M. Huang and J.K. Lin, Drug Metabolism \& Disposition, 27(4), 486 (1999).

12. W. Liu, Y. Zhai, X. Heng, F.Y. Che, W. Chen, D. Sun, et al., Journal of Drug Target, 24(8), 694 (2016), DOI: $10.3109 / 1061186 X .2016 .1157883$

13. X. Fang, L. Fang, S. Gou and L. Cheng, Bioorganic \& Medicinal Chemistry Letters, 23, 1297 (2013), DOI: $10.1016 /$ j.bmcl.2012.12.098

14. V. Kumar, K. Kaur, G.K. Gupta and A.K. Sharma, European Journal of Medicinal Chemistry, 69, 735 (2013), DOI: 10.1016/j.ejmech.2013.08.053

15. K. Karrouchi, S. Radi, Y. Ramli, J. Taoufik, Y.N. Mabkhot, F.A. Al-Aizari, et al., Molecules, 23, 134 
RASĀYAN J. Chem.

Vol. 12 | No. 2 |471 - 477| April - June | 2019

(2018), DOI:10.3390/molecules23010134

16. K.A. Kumar and P. Jayaroopa, International Journal of Pharmaceutical, Chemical and Biological Sciences, 3(2), 294 (2013).

17. A. Ansari, A. Ali, M. Asif and Shamsuzzaman, New Journal of Chemistry, 41, 16(2017), DOI: $10.1039 / \mathrm{C} 6 \mathrm{NJ} 03181 \mathrm{~A}$

18. G. Frenzer and W.F. Maier, Annual Review of Materials Research, 36, 281(2006), DOI: 10.1146/annurev.matsci.36.032905.092408

19. J.N. Naat, T. Lapailaka, A. Sabarudin, and R.T. Tjahjanto, Rasayan Journal of Chemistry, 11(4), 1467(2018), DOI: 10.31788/RJC.2018.1144055

20. K. Phukan, A. Jain and N. Devi, Research Journal of Chemistry and Environment, 15(1), 86(2011).

21. P. Alexander, M. Jainamboo, P.K. Praseetha, and S.T. Gopukumar, Rasayan Journal of Chemistry, 9(3), 300(2016).

22. H. Kusumastuti, W. Trisunaryanti, I.Z. Falah, M.F. Marsuki, Rasayan Journal of Chemistry, 11(2), 522(2018), DOI: $10.31788 /$ RJC.2018.1122061

23. A.P.L. Batista, H.W.P. Carvalho, G.H.P. Luz, P.F.Q. Martins, M. Goncalves and L.C.A. Oliviera, Environmental Chemistry Letters, 8, 63 (2010), DOI: 10.1007/s10311-008-0192-8

24. R. Neumann and M. Levin-Elad, Journal of Catalysis, 166, 206(1997), DOI: 10.1006/jcat.1997.1479

25. T. Tenkyong, N. Bachan, J. Raja, P.N. Kumar and J.M. Shyla, Materials Science-Poland, 33(4), 826 (2015), DOI: $10.1515 / \mathrm{msp}-2015-0097$

26. A.S. Ethiraj and D.J. Kang, Nanoscale Research Letters, 7, 70(2012), DOI:10.1186/1556-276X-7-70

27. N.M. Ahmed and M.M. Selim, Anti-Corrosion Methods and Materials, 57, 133(2010), DOI:10.1108/00035591011040092

28. H.R. Puneeth and S.A. Chandrashekariah, International Journal of Pharmacy and Pharmaceutical Sciences, 7(4), 244(2015).

29. J. Das, S. Pany, S. Panchal, A. Majhi and G.M. Rahman, Bioorganic \& Medicinal Chemistry, 19, 6196 (2011), DOI:10.1016/j.bmc.2011.09.011

[RJC-5011/2018] 